\title{
Incidence and management of ulcerative keratitis in a pinnipeds population under human care
}

Francesco Grande ${ }^{1}$, Letizia Fiorucci ${ }^{1 *}$, Roberto Macrelli ${ }^{2}$ and Pietro Saviano ${ }^{3}$

*Correspondence: letiziafiorucci@gmail.com

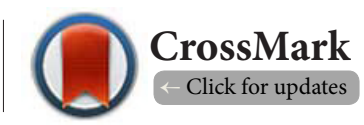

'Zoomarine Italia SpA, Rome, 00071, Italy.

${ }^{2}$ Department of Pure and Applied Sciences, University of Urbino, Urbino, 61029, Italy.

${ }^{3}$ Ambulatorio Veterinario Saviano-Larocca, Spezzano, 41042, Italy.

\begin{abstract}
Background: Despite limited information, topical drug combinations are being routinely used for the treatment keratitis in pinnipeds.Corneal alterations in pinnipeds, as in other animal species, can be cause of severe pain and the intensity of discomfort can vary in the affected subjects. Late diagnosis or untimely treatment can lead to dramatic developments even in case of minor corneal diseases, with sometimes disastrous consequences for the globe up to loss of vision.
\end{abstract}

Methods: During five years a small population of different species, age and sex, kept under human care, was submitted to a complete daily ophthalmological evaluation and to a treatment when necessary.

Results: The ulcerative keratitis was a relatively frequent pathology (seven of 15 subjects for a total of 76 episodes). Six of 7 patients (85.7\%) showed lesions simultaneously in both eyes at least once. The average time elapsing between the ulcer diagnosis and the healing of the same was about 32 days ( $\sigma= \pm 18$ days) with a minimum of 3 and a maximum of 74 days. In cases where the therapy has been conducted, the onset ulcer until its resolution, with the same $\operatorname{drug}(\mathrm{n}=6)$, were obtained average values of 28.6 days $(\sigma= \pm 17.07$ days) in the case of netilmicin, 27.5 days ( $\sigma= \pm 6.56$ days) for tobramycin, and 41.95 days $(\sigma= \pm 9.69$ days) for gentamycin. The difference between these values was statistically not significant $(p=0.9)$ for netilmicin and tobramycin while for the group treated only with gentamycin, the difference was detected statistically significant compared with netilmicin and tobramycin ( $\mathrm{p}=0.048$ and $\mathrm{p}=0.042$ respectively). In two cases $(\mathrm{n}=2)$ it was considered necessary to associate local therapy with systemic therapy using doxycycline and non-steroidal anti-inflammatory drugs. In these cases the resolution has taken place in 31 days ( $\sigma= \pm 16.65$ days). In four cases $(n=4)$ autologous plasma has been added to local therapy. In eleven cases $(n=7)$ it was necessary to use local osmotic agents (sodium chloride $5 \%$, glucose $35 \%$ ) to solve the edema.

Conclusions: Due to the anatomical and physiological characteristics of the pinnipeds eye, the best medical treatment for corneal lesions in our experience was the use of antibiotic collyrium associated with hyperosmotic solution in case of edema and platelet rich plasma (PRP) to support the healing, considering an administration frequency 3-4 times/day at least.

Keywords: Pinnipeds, ulcerative keratitis, incidence, management, Shapiro-Wilk test

\section{Introduction}

Eye diseases are quite common in pinnipeds, both in wild or under human care population [1-4]. Among the ocular disorders more frequent in these marine mammals there are certainly those of the cornea, with a wide range of clinical presentations from keratitis localized and not complicated to more or less deep or infected ulcers $[5,6]$. Corneal alterations in pinnipeds, as in other animal species, can be cause of severe pain and the intensity of discomfort can vary in the affected subjects. Late diagnosis or untimely treatment can lead to dramatic developmentseven in case of minor corneal diseases, with sometimes disastrous consequences for the globe up to loss of vision [7]. 
This study aims to illustrate the various medical treatment options feasible in pinnipeds suffering from corneal ulcer, describing the incidence and management of the disease in a small population kept under human care, in order to provide useful data to a better understanding of so frequent problems.

\section{Materials and methods}

This study included twoSouth African Fur Seals (Arctocephaluspusilluspusillus), fourSouth American Sea lions (Otariaflavescens), fourCalifornia Sea Lions (Zalophuscalifornianus), threeGrey Seals (Halichoerusgrypus) and twoHarbor Seals (Phocavitulina), for a total of 7 males and 8 females (Weight: Mean $125.2 \pm 24.4$ kg; Min-Max: $38.5-329.06 \mathrm{~kg}$ ). The age of each individual was calculated taking as reference the date of the beginning of the study.The mean age of subjects was $13 \pm 6$ years (Min-Max:1-23 years). The water was an artificial salt water, disinfected by chlorine, average water temperature was $23^{\circ} \mathrm{C}\left(73.4^{\circ} \mathrm{F}\right)$. The study was carried out from 2011 to 2015 . During the observation period, all subjects were submitted to a complete clinical examination that included a daily ophthalmological evaluation. The population was divided into groups according to the different drugs used for therapy (" $n$ " represents the number of subjects, "cases" areketatitis episodes). The normality in the distribution of the values of these groups was demonstrated by the ShapiroWilk test. The average values of the time needed for healing have been corrected by means of standard deviation $(\sigma)$. The Student $t$ test was used to assess the statistical significance in the comparison between these average values. Values of $\mathrm{P}<0.05$ were considered statistically significant. It was not possible to trace in all cases the depth and extent of ulcer, so the results do not include this data. For the therapy both topical and systemic medications were administered. The topical molecules used were tobramycin $0.3 \%$ in solution (TOBRAL ${ }^{\circledR}$ eye drops, Alcon SpA Italy), netilmicin $0.3 \%$ in solution (NETTACIN ${ }^{\circledR}$ eye drops, SifiSpA), 0.3\% gentamycin in solution (RIBOMICIN ${ }^{\circledast}$ eye drops, FarmigeaSpA), 35\% glucose solution (35\% GLUCOSE ${ }^{\circledR}$ ophthalmic gel, Tubilux Pharma $\mathrm{SpA}$ ), sodium chloride $5 \%$ solution (eye drops EDENORM ${ }^{\oplus}$, Sooft Italy srl). In some cases it has also been employed autologous plasma obtained by centrifugation of whole blood collected from the same subject treated. The molecules used for systemic use have been doxycycline oral use $10 \mathrm{mg} / \mathrm{Kg}$ (RONAXAN ${ }^{\circledast}$, Italy S.p.A. Merial), meloxicam oral use $0.05 \mathrm{mg} /$ $\mathrm{Kg}$ (METACAM ${ }^{\circledast}$, Boehringer Ingelheim S.p.A.). The choice of these antibiotic has been intentionally limited to prevent the onset of drug resistance.

\section{Results}

In the population of pinnipeds observed $(n=15)$, the ulcerative keratitis was a relatively frequent pathology (seven of 15 subjects for a total of 76 episodes). Six of 7 patients (85.7\%) showed lesions simultaneously in both eyes at least once.The average age of affected animals was 10 years and 6 months.
In 34 episodes, the disease had a bilateral event.The average time elapsing between the ulcer diagnosis and the healing of the same was about 32 days ( $\sigma= \pm 18$ days) with a minimum of 3 and a maximum of 74 days. In cases where the therapy has been conducted, the onset ulcer until its resolution, with the same drug $(n=6)$, were obtained average values of 28.6 days ( $\sigma= \pm 17.07$ days) in the case of netilmicin, 27.5 days ( $\sigma= \pm 6.56$ days) for tobramycin, and 41.95 days ( $\sigma= \pm 9.69$ days) for gentamycin. The difference between these values was statistically not significant $(p=0.9)$ for netilmicin and tobramycin while for the group treated only with gentamycin, the difference was detected statistically significant compared with netilmicin and tobramycin $(p=0.048$ and $p=0.042$ respectively). In two cases $(n=1)$ the evolution of the disease has required a change in therapy. In these cases the average time until healing was 53.25 days ( $\sigma= \pm 19.69$ days). In two cases $(n=2)$ it was considered necessary to associate local therapy with systemic therapy using doxycycline and non-steroidal anti-inflammatory drugs. In these cases the resolution has taken place in 31 days $(\sigma= \pm 16.65$ days). In four cases $(n=4)$ autologous plasma has been added to local therapy. In eleven cases $(n=7)$ it was necessary to use local osmotic agents (sodium chloride 5\%, glucose $35 \%$ ) glucose to solve the edema.

\section{Discussion}

The results confirmed the literature [1-4]. Comparing with other authors [5], a lower incidence of the phenomenon in our population resulted $(46.6 \%$ versus $64.6 \%$ of individuals affected), but it is important to consider how in her study, Colitzalso includes individuals with localized corneal opacities and signs of ocular discomfort but without ulceration. The prevalence of bilateral presentations was high (34 of $76 \mathrm{epi}$ sodes). It is interesting to note that all individuals belonging to the Otariaflavescens species have been suffering from at least one episode of corneal ulcer during the study, while specimen belonging to the species Halichoerusgrypus did not present any episode, however breed differences cannot be evaluated on a small number of patients. Regarding the incidence based on the times, corneal ulcers were more common in the period between December and June, this period coincides with the six months ranging from the winter to the summer solstice, a time when the days get longer. The corneal ulcers are associated with a certain degree of edema which can be localized to the lesion margins (perilimbale), or extend to the entire corneal surface (Figures $\mathbf{1 a}$ and $\mathbf{1}$ b). It can cause a thickening of the cornea such as to alter the perception of the real depth of the lesionand, at times, a certain degree of conjunctival pigmentation with extension in the cornea can be present. Mostly in these species the vascularization is necessary for the resolution of deeper lesions to avoid delayed or and stunted healings (Figure 1c) [5]. The cornea ulcers therapy includes topical antibiotics in the form of eyedrops. The gentamycin, netilmicin and tobramycin are the most widely used drugs 


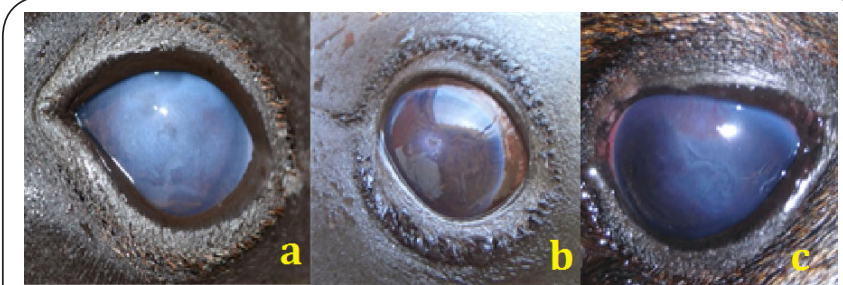

Figure 1. Arctocephalus pusillus, $17 \mathrm{y}$, male, ulcerative keratitis with diffuse edema (a); Otaria flavescens, 20, female, ulcerative keratitis with perilimbal edema (b); Arctocephaluspusillus pusillus, $23 \mathrm{y}$, male, corneal vascularization (c). and systemic anti-inflammatory drugs may be indicated. Eye drops made from $2 \%$ cyclosporine or tacrolimus $0.03 \%$ can contribute to the management of the disease due to their ability to restore surface tolerance to antigens, it is important to remember that an immune system, locally, is damage could be a risk factor [5]. Due to the anatomical and physiological characteristics of the pinnipeds eye, the best medical treatment for corneal lesions in our experience was the use of antibiotic collyrium associated with hyperosmotic solution in case of edema and platelet rich plasma (PRP) to support the healing, considering an administration frequency 3-4 times/ day at least (Figures 3a-3d). According to the literature [11], A key role in the management of corneal lesions is the control

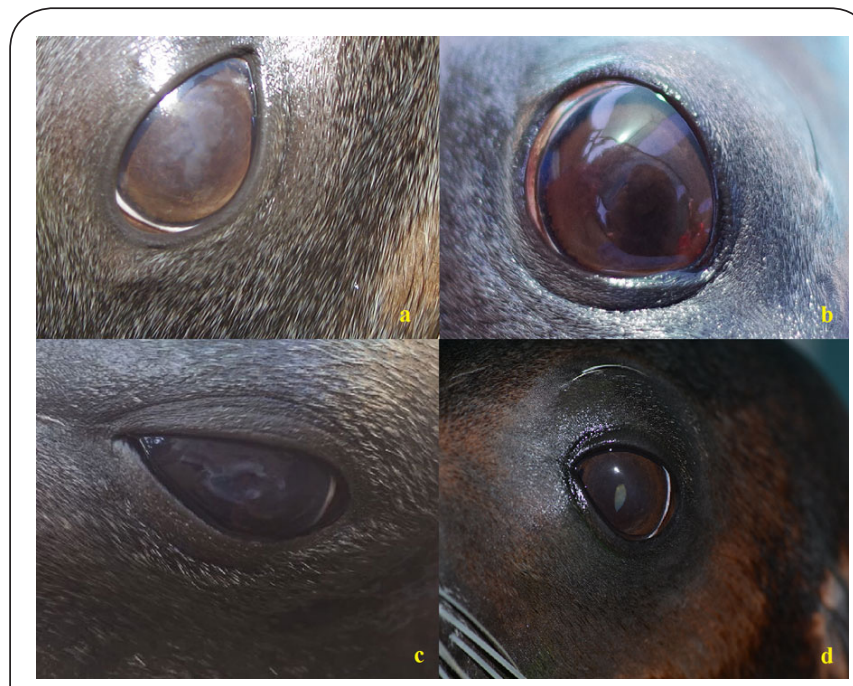

Figure 3. Zalophuscalifornianus, 12 y, female, ulcerative keratitis: 3a (right eyebefore treatment), $\mathbf{3 b}$ (right eyeafter treatment), 3c (lefteyebefore treatment), 3d (lefteyeafter treatment).

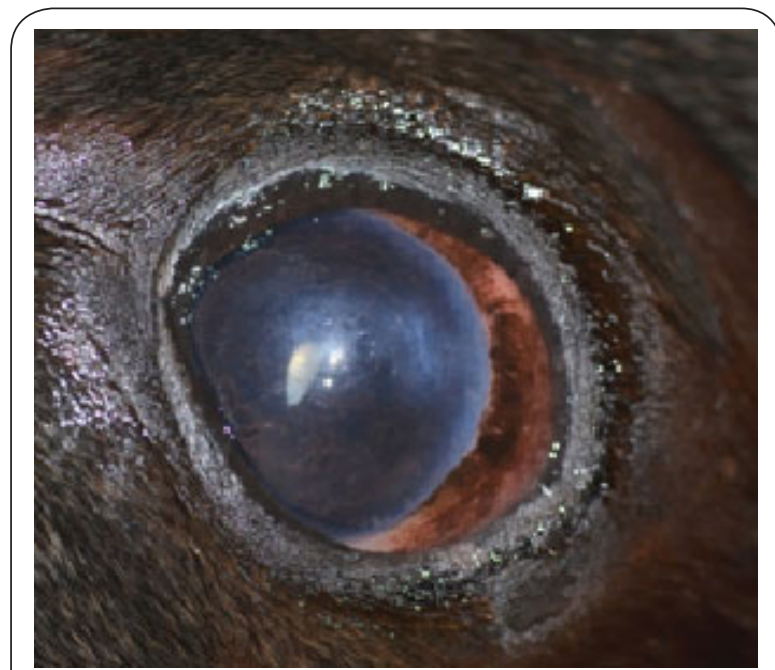

Figure 2. Arctocephalus pusillus, $23 \mathrm{y}$, male, corneal bubbles typical of bullous keratopathy. of the "risk factors" such as the ultraviolet radiation from the sun.The ability of UV rays from damaging all corneal layers has been widely proven $[\mathbf{1 , 4 , 5 , 1 1 ]}$. Another clinical signis the reduction of the signs of ocular discomfort, such as blepharospasm, when the color and the material used in the construction of the tanks limiting the production of reflections and glare. To prevent oxidative damage caused by UV rays, as well as provide shaded areas where the animals can take shelter from the sun, you can use rich dietary supplements of antioxidants [8]. Finally, the water quality: the salinity, the concentration of nitrogen compounds, the temperature, the type of disinfectant agents used and the concentration of coliform organisms have all been recognized as possible factors able to influence the onset and evolution of corneal ulcers in pinnipeds, and are studied at present [1].

\section{Competing interests}

The authors declare that they have no competing interests. 
Grande et al. Veterinary Medicine and Animal Sciences 2017,

http://www.hoajonline.com/journals/pdf/2054-3425-5-1.pdf

Authors' contributions

\begin{tabular}{|l|c|c|c|c|}
\hline Authors' contributions & GF & FL & MR & SP \\
\hline Research concept and design & $\checkmark$ & $\checkmark$ & -- & $\checkmark$ \\
\hline Collection and/or assembly of data & $\checkmark$ & $\checkmark$ & -- & $\checkmark$ \\
\hline Data analysis and interpretation & $\checkmark$ & $\checkmark$ & $\checkmark$ & $\checkmark$ \\
\hline Writing the article & -- & $\checkmark$ & -- & -- \\
\hline Critical revision of the article & -- & $\checkmark$ & $\checkmark$ & -- \\
\hline Final approval of article & $\checkmark$ & $\checkmark$ & $\checkmark$ & $\checkmark$ \\
\hline Statistical analysis & -- & $\checkmark$ & $\checkmark$ & -- \\
\hline
\end{tabular}

\section{Acknowledgement}

We would like to thank all the staff of veterinarians and trainers, especially Dr. Giorgia Di Stefano as the Zoomarine Pinnipeds trainers chief, who dedicate themselves daily to animal welfare. Their work makes medical behaviours possible.

\section{Publication history}

Editor: Cengiz Gokbulut, Balikesir University, Turkey. Received: 03-May-2017 Final Revised: 10-Jun-2017

Accepted: 29-Jun-2017 Published: 14-Jul-2017

\section{References}

1. Colitz CM, Renner MS, Manire CA, Doescher B, Schmitt TL, Osborn SD, Croft L, Olds J, Gehring E, MergI J, Tuttle AD, Sutherland-Smith M and Rudnick JC. Characterization of progressive keratitis in otariids. Vet Ophthalmol. 2010; 13 Suppl:47-53. | Article | PubMed

2. Gelatt KN. Veterinary Ophthalmology. 4th ed. Oxford (UK): Blackwell Publishing; 2007.

3. Miller SN, Colitz CM and Dubielzig RR. Anatomy of the California sea lion globe. Vet Ophthalmol. 2010; 13 Suppl:63-71. | Article I PubMed

4. Stoskopf MK, Zimmerman S, Hirst LW and Green R. Ocular anterior segment disease in northern fur seals. J Am Vet Med Assoc. 1985; 187:1141-4. | PubMed

5. Gage LJ. Captive Pinniped Eye Problems, We Can do Better!.JMATE. 2011; 4:25-28.

6. Gerber JA, Roletto J, Morgan LE, Smith DM and Gage LJ. Findings in pinnipeds stranded along the central and northern California coast, 1984-1990. J Wildl Dis. 1993; 29:423-33. | Article | PubMed

7. Klauss G, Suedmeyer WK, Galle LE, Giuliano EA and Castaner LJ. Surgical resection of an orbital fat prolapse in a California sea lion (Zalophus californianus). Vet Ophthalmol. 2005; 8:277-81. | Article | PubMed

8. Freeman KS, Thomasy SM, Stanley SD, Van Bonn W, Gulland F, Friedlaender AS and Maggs DJ. Doxicycline Concentration in the Tears of Pinnipeds Following Oral Drugs Administration. Vet Ophthalmol. 2011; 14:406-422.

9. Alio JL, Abad M, Artola A, Rodriguez-Prats JL, Pastor S and Ruiz-Colecha J. Use of autologous platelet-rich plasma in the treatment of dormant corneal ulcers. Ophthalmology. 2007; 114:1286-1293 e1. | Article | PubMed

10. Colitz CMH, Saville WJA, Renner MS, Chittick EJ, Clough P, Collins S, Dalton L, Dold C, Dugan S, Knightly F, McBainJ and Walsh M. Tear film analysis of Orcinus Orca. Vet Ophthalmol. 2007; 10:398-411.

11. Oliva MS and Taylor H. Ultraviolet radiation and the eye. Int Ophthalmol Clin. 2005; 45:1-17. | Article | PubMed

\section{Citation:}

Grande F, Fiorucci L, Macrelli R and Saviano P. Incidence and management of ulcerative keratitis in a pinnipeds population under human care. Vet Med Anim Sci. 2017; 5:1. http://dx.doi.org/10.7243/2054-3425-5-1 